\title{
A yeast expression system for functional and pharmacological studies of the malaria parasite $\mathrm{Ca}^{2+} / \mathrm{H}^{+}$antiporter
}

\author{
J Enrique Salcedo-Sora*, Steve A Ward and Giancarlo A Biagini
}

\begin{abstract}
Background: Calcium $\left(\mathrm{Ca}^{2+}\right)$ signalling is fundamental for host cell invasion, motility, in vivo synchronicity and sexual differentiation of the malaria parasite. Consequently, cytoplasmic free $\mathrm{Ca}^{2+}$ is tightly regulated through the co-ordinated action of primary and secondary $\mathrm{Ca}^{2+}$ transporters. Identifying selective inhibitors of $\mathrm{Ca}^{2+}$ transporters is key towards understanding their physiological role as well as having therapeutic potential, therefore screening systems to facilitate the search for potential inhibitors are a priority. Here, the methodology for the expression of a Calcium membrane transporter that can be scaled to high throughputs in yeast is presented.
\end{abstract}

Methods: The Plasmodium falciparum $\mathrm{Ca}^{2+} / \mathrm{H}^{+}$antiporter (PfCHA) was expressed in the yeast Saccharomyces cerevisiae and its activity monitored by the bioluminescence from apoaequorin triggered by divalent cations, such as calcium, magnesium and manganese.

Results: Bioluminescence assays demonstrated that PfCHA effectively suppressed induced cytoplasmic peaks of $\mathrm{Ca}^{2+}$, $\mathrm{Mg}^{2+}$ and $\mathrm{Mn}^{2+}$ in yeast mutants lacking the homologue yeast antiporter Vcx1p. In the scalable format of 96-well culture plates pharmacological assays with a cation antiporter inhibitor allowed the measurement of inhibition of the $\mathrm{Ca}^{2+}$ transport activity of PfCHA conveniently translated to the familiar concept of fractional inhibitory concentrations. Furthermore, the cytolocalization of this antiporter in the yeast cells showed that whilst PfCHA seems to locate to the mitochondrion of $P$. falciparum, in yeast PfCHA is sorted to the vacuole. This facilitates the real-time $\mathrm{Ca}^{2+}{ }^{2+}$ loading assays for further functional and pharmacological studies.

Discussion: The functional expression of PfCHA in S. cerevisiae and luminescence-based detection of cytoplasmic cations as presented here offer a tractable system that facilitates functional and pharmacological studies in a highthroughput format. PfCHA is shown to behave as a divalent cation $/ \mathrm{H}^{+}$antiporter susceptible to the effects of cation/ $\mathrm{H}^{+}$ inhibitors such as KB-R7943. This type of gene expression systems should advance the efforts for the screening of potential inhibitors of this type of divalent cation transporters as part of the malaria drug discovery initiatives and for functional studies in general.

Conclusion: The expression and activity of the PfCHA detected in yeast by a bioluminescence assay that follows the levels of cytoplasmic $\mathrm{Ca}^{2+}$ as well as $\mathrm{Mg}^{2+}$ and $\mathrm{Mn}^{2+}$ lend itself to high-throughput and quantitative settings for pharmacological screening and functional studies.

Keywords: Calcium, Magnesium, Manganese, Malaria, Yeast, Plasmodium, $\mathrm{Ca}^{2+} / \mathrm{H}^{+}$antiporter, Saccharomyces cerevisiae, Vacuole

\footnotetext{
* Correspondence: esalcedo@liverpool.ac.uk; biagini@liverpool.ac.uk

Liverpool School of Tropical Medicine, Pembroke place, Liverpool L3 5QA, UK
} 


\section{Background}

$\mathrm{Ca}^{2+}$ signalling drives a myriad of events in the Plasmodium. falciparum life cycle. They include erythrocyte invasion [1-3], in vivo synchronicity in the erythrocytic cycle [4], together with sexual differentiation, motility and invasion by ookinetes and sporozoites in the mosquito vector [5-7]. As in any eukaryote the parasite's concentration of cytosolic free $\mathrm{Ca}^{2+}$ is tightly maintained at $50-150 \mathrm{nM}[8,9]$. In eukaryotes this is achieved by its active sequestration into various organelles and/or extrusion to extracellular space. Transporters that could mediate this activity in P. falciparum include two $\mathrm{Ca}^{2+}$ ATPases, a low-affinity transporter PfATP4 [10] and a higher affinity SERCAlike $\mathrm{Ca}^{2+}$ ATPase PfATP6 [11,12]. Intracellular $\mathrm{Ca}^{2+}$ in Plasmodium has been found in acidic compartments (e.g. food vacuole with a calculated free $\mathrm{Ca}^{2+}$ of $0.4-2 \mu \mathrm{M}$ ) $[9,13,14] . \mathrm{Ca}^{2+}$ sequestration has also been observed in the malaria parasite's mitochondrion $[15,16]$. Besides $\mathrm{Ca}^{2+}$ pumps, low-affinity secondary transporters that facilitate the membrane transport of $\mathrm{Ca}^{2+}$ and other divalent cations (e.g. $\mathrm{Mg}^{2+}, \mathrm{Mn}^{2+}$ ) into organelles or through plasma membrane using a proton (in lower eukaryotes and plants) gradient in the opposite direction $\left(\mathrm{Ca}^{2+} / \mathrm{H}^{+}\right.$exchangers or antiporters) are known to mediate the dissipation of cytoplasmic peaks of $\mathrm{Ca}^{2+}[17,18]$. In this context a $P$. falciparum $\mathrm{Ca}^{2+} / \mathrm{H}^{+}$antiporter (PfCHA) homologue to the family of CAtion eXchangers (CAX, Transporter Classification Database 2.A.19.2) [19] has been reported and characterized in oocytes of $X$. laevis as a divalent cation $\left(\mathrm{Ca}^{2+}, \mathrm{Mn}^{2+}\right.$ and possibly $\left.\mathrm{Mg}^{2+}\right) / \mathrm{H}^{+}$exchanger [20].

Saccharomyces cerevisiae is a highly developed and widely used model organism. Furthermore, S. cerevisiae has become a model for eukaryotic $\mathrm{Ca}^{2+}$ homeostasis $[21,22]$. In the present work, PfCHA has been expressed in the yeast $v c x 1 \Delta$ (VaCuolar $\mathrm{Ca}^{2+} / \mathrm{H}^{+}$eXchanger) gene knock-out mutant. A bioluminescence apoaequorin reporter system has been used to allow the detection of cytoplasmic $\mathrm{Ca}^{2+}$ in $v c x 1 \Delta$ where PfCHA is shown to be able to re-establish $\mathrm{Ca}^{2+}$ mobilisation from cytoplasm. In the apoaequorin system aequorin catalyses the oxidation of an imidazolopyrazinone (coelenterazine) upon $\mathrm{Ca}^{2+}$ binding and light is emitted from the oxidized and excited state of this chromophore that exists tightly bound to aequorin. In vitro, $\mathrm{Ca}^{2+}$ binding to apoaequorin triggers the emission of blue light (469 $\mathrm{nm}$ ), although other activating cations such as trivalent lanthanides [23] and divalent $\mathrm{Mn}^{2+}$ and $\mathrm{Mg}^{2+}$ are also known to bind aequorin via three EF-hand $\mathrm{Ca}^{2+}$-binding sites [24].

Interestingly, whilst in the parasite $\mathrm{PfCHA}$ is reported to be sorted to the mitochondrion [20], in S. cerevisiae the exchanger is sorted to the vacuole. This finding offers further practical advantages for the studies of a membrane transporter such as PfCHA since yeast vacuoles are their main $\mathrm{Ca}^{2+}$ storage compartments. Yeast is an attractive organism for recombinant protein production as it combines highly developed genetic systems and ease of use with reductions in time and costs. Moreover, due to the challenging nature of expressing functional membrane proteins a yeast expression system for PfCHA is a valuable tool for further functional studies and pharmacological screens. To this extent, the 96well format was used to further demonstrate divalent cation (i.e. $\mathrm{Ca}^{2+}, \mathrm{Mg}^{2+}, \mathrm{Mn}^{2+}$ ) transport by PfCHA in $v c x 1 \Delta$ yeast cells and present an inhibition assay with a cation antiporter inhibitor as a proof of concept of the opportunities offered by this expression system for the search of PfCHA inhibitors.

\section{Methods}

\section{Gene cloning}

Total RNA from P. falciparum 3D7 was extracted with Trizol (Invitrogen) following manufacturer's protocol using parasites harvested from standard cultures [25]. Gene sequences used as reference were downloaded from PlasmoDB5.3 [26] and GenBank [27]. The polymerase chain reaction (PCR) product from total RNA for PFF0170w (PfCHA) was cloned in the pCRII-Topo vector (Invitrogen), and subcloned in the shuttle vectors of the pGREG series [28] between NotI and BamHI restriction sites obtained from Euroscarf. Primers for PFF0170w were 5'ATGGTTATGGGTAGAGTTC and 5'TTATGAT GTATCAAACCAG. The $S$. cerevisiae $V C X 1$ gene was directly cloned into pGREG505 using the following primers: 5'-gaattcgatatcaagcttatcgataccgtcgacaGGCTGCTGATAG CAAATAAA and 5'- gcgtgacataactaattacatgactcgaggtcgac GAATTTCTGCGCTACTGTTC. pGREG505 vector has the LEU2 selectable marker and the GAL1 promoter. Escherichia coli TOP10 cells (Invitrogen) were routinely used as recombinant plasmids host. For bioluminescence measurements of cytosolic $\mathrm{Ca}^{2+}$ yeast cells were transformed with a plasmid carrying the aequorin gene [29]. This gene cloned in a pSEY8 plasmid under $A D H 3$ promoter was kindly provided by David M. Bedwell (University of Alabama at Birmingham). Reverse transcription PCR and real-time PCR with iQ SYBR Green Supermix (Bio$\mathrm{Rad}$ ) in yeast were performed using total RNA extracted with RiboPure-Yeast (Ambion/Applied Biosystems, Austin, TX, USA) following manufacturer's instructions. cDNA was synthesized using ThermoScript (Invitrogen), and PCR amplifications using Platinum Taq High Fidelity (Invitrogen).

\section{Yeast strains and media}

Yeast Saccharomyces cerevisiae haploid strain Y03825

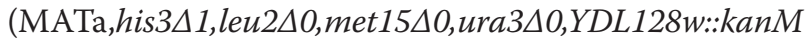

X4) was obtained from the European Saccharomyces cerevisiae Archives for Functional Analysis (Euroscarf) 
[30]. In Y03825 the $\mathrm{Ca}^{2+}$ antiporter gene $V C X 1$ (YDL128w, [31]) is replaced by the kanMX4 gene that in yeast provides a geneticin (G418, Sigma G8168) resistant phenotype. BY4741n is the isogenic and haploid parental strain (Euroscarf Y00000). Yeast cells were transformed by the DMSO-based method [32]. Yeast were grown on complete YPD (yeast-peptone) medium with $2 \%(w / v) ~ D-$ glucose, or minimal synthetic medium (SM) with $2 \%$ (w/ v) glucose or $2 \%(\mathrm{w} / \mathrm{v})$ galactose as carbon sources, and strain-specific required nutrients and $400 \mu \mathrm{g} / \mathrm{ml} \mathrm{G418}$ [33].

\section{Apoaequorin luminescence assay}

Apoaequorin assays were adapted from Miseta et al [34]. pSEY8 vector (pAEQ with a URA3 selection marker) expresses the soluble calcium-binding protein aequorin [29]. Cells carrying pSEY8 and the pGREG505 recombinant vectors were grown in SD and 2\% (w/v) glucose until they reached exponential growth to $0.5-0.6 \mathrm{OD}_{600} / \mathrm{ml}$. The cultures were then washed twice in SD medium and grow a further four hours in SD with $2 \%(w / v)$ galactose to induced gene expression. Ten $\mathrm{OD}_{600}$ units of cells were resuspended in $180 \mu \mathrm{l}$ of test medium -TM- $(0.17 \%(\mathrm{w} / \mathrm{v})$ YNB, 2 mM EGTA, 40 mM MES-Tris, pH 6.5) after two washes with the same medium. To equilibrate cytosolic aequorin with its allosteric group, $20 \mu \mathrm{l}$ of $0.6 \mathrm{mM}$ coelenterazine (Fluka Biochemica 07372) dissolved in methanol were added and the cell suspension incubated for $30 \mathrm{~min}$ at room temperature. Cells were then washed twice in TM. The final pellet was resuspended in $1 \mathrm{ml}$ of TM and allowed to equilibrate for $30 \mathrm{~min}$ at room temperature. After detecting the baseline light emission $1 \mathrm{ml}$ of $1 \mathrm{M}$ of $\mathrm{CaCl}_{2}$ was added. Final concentrations of $\mathrm{CaCl}_{2}$ were 50 $\mathrm{mM}$ or $500 \mathrm{mM}$ in $2 \mathrm{ml}$ total volume. For the multi-well plate experiments $0.1 \mathrm{OD}_{600}$ were plated in $0.1 \mathrm{ml}$ volumes and $1 \mathrm{M}$ of the divalent cation salts $\left(\mathrm{CaCl}_{2}\right.$, $\mathrm{MgCl}_{2}$ or $\mathrm{MnCl}_{2}$ ) were added in $0.1 \mathrm{ml}$ to make $0.5 \mathrm{M}$ final concentrations in $0.2 \mathrm{ml}$ total volume. Light emission was collected from the $2 \mathrm{ml}$ assays with a CliniLumat Berthold luminometer at intervals of 2 seconds or from the $0.2 \mathrm{ml}$ multi-well assays with a LumiStarOmega luminometer (BMG Labtech) plate reader at 0.5 seconds intervals. Where indicated the samples were incubated with dimethylsulphoxide (DMSO) alone or with Bafilomycin $\mathrm{A}_{1}$ dissolved in DMSO $(1 \mu \mathrm{M}$ final concentration, Sigma B1793) or KB-R7943 dissolved in DMSO (Calbiochem 420336) for 30 minutes at room temperature prior to the addition of $\mathrm{CaCl}_{2}$.

\section{Indirect immunofluorescence assay (IFA)}

Yeast membranes were extracted and purified as in Fisher et al [35]. Indirect immunofluorescence in yeast cells was performed as in Stearman et al [36]. Polyclonal IgG antibody Anti-PfCHA $(0.568 \mathrm{mg} / \mathrm{ml})$ was produced in rabbit by GenScript (Piscataway, NJ, USA) against a 14 aa synthetic peptide representing positions 73-86 in the amino terminal sequence of PfCHA and used at 1:100 dilutions. The Anti-actin antibody was purchased from Sigma (A2066) and used at 1:500 dilutions. The secondary antibody anti-rabbit IgG-FITC was also purchased from Sigma (F0382) and used at 1:1000 dilutions. Cells were mounted with VectaShield HardSetTM mounting medium (Vector Labs Burlingame, CA, USA) and observed in a confocal microscope Zeiss Axiovert 200 M (L5M 5Pascal laser modules). Propidium iodide (Fluka 70335) was used for nuclei localization at $10 \mu \mathrm{g} / \mathrm{ml}$ room temperature for 30 minutes after treating with 100 $\mu \mathrm{g} / \mathrm{ml}$ of RNaseA for 30 minutes.

\section{Results \\ PfCHA restores mobilization of cytoplasmic $\mathrm{Ca}^{2+}$ in Saccharomyces cerevisiae vcx1 $1 \Delta$}

Yeast $v c x 1 \Delta$ has a significant defect in the rapid $\mathrm{Ca}^{2+}$ sequestration response to high cytosolic levels of this cation [34]. Recombinant pGREG505 vectors carrying PfCHA or yeast $V C X 1$ genes as well as the empty vector control were transformed into $v c x 1 \Delta$. For the detection of cytosolic $\mathrm{Ca}^{2+}$ by bioluminescence, these strains were subsequently transformed with a vector carrying the apoaequorin gene (pSEY8-AEQ). Positive colonies were selected for growth in the absence of leucine and uracil and in the presence of $400 \mu \mathrm{g} / \mathrm{ml}$ of geneticin in SD medium. The presence of the recombinant vectors was verified and their RNA expression monitored by reverse transcription and PCR amplification (Additional file 1). Expectedly, there is a relative low expression of the heterologous PfCHA gene in the $v c x 1 \Delta$ mutant in comparison to the native yeast $V C X 1$ gene. Truncated gene transcription is a known phenomenon in yeast expressing AT-rich $P$. falciparum genes [37] and this is evident in the differential amplifications for fragments in comparison to fulllength $V C X 1$ and PfCHA genes (Additional file 1B). Nonetheless the bioluminescence assays as presented below showed that these levels of expression were sufficient to detect functional protein in the yeast $v c x 1 \Delta$ background.

The medium used to process cells for the apoaequorin bioluminescence assays contains 2 mM EGTA to reduce extracellular $\mathrm{Ca}^{2+}$ concentration in the test medium - TM ( $6 \mu \mathrm{M}[34])$. Four different samples were examined: the parental isogenic and haploid strain BY4741n, the $v c x 1 \Delta$ mutant containing the pGREG505 vector only $(v c x 1 \Delta+$ p505), $v c x 1 \Delta$ carrying the recombinant pGREG505-VCX1 $(v c x 1 \Delta+V C X 1)$, and $v c x 1 \Delta$ carrying the recombinant vector pGREG505 with PfCHA ( $v c x 1 \Delta+\mathrm{PfCHA})$. All four strains responded with a sharp elevation in cytosolic $\mathrm{Ca}^{2+}$ levels when $50 \mathrm{mM} \mathrm{CaCl}_{2}$ was added (Figure 1A). 

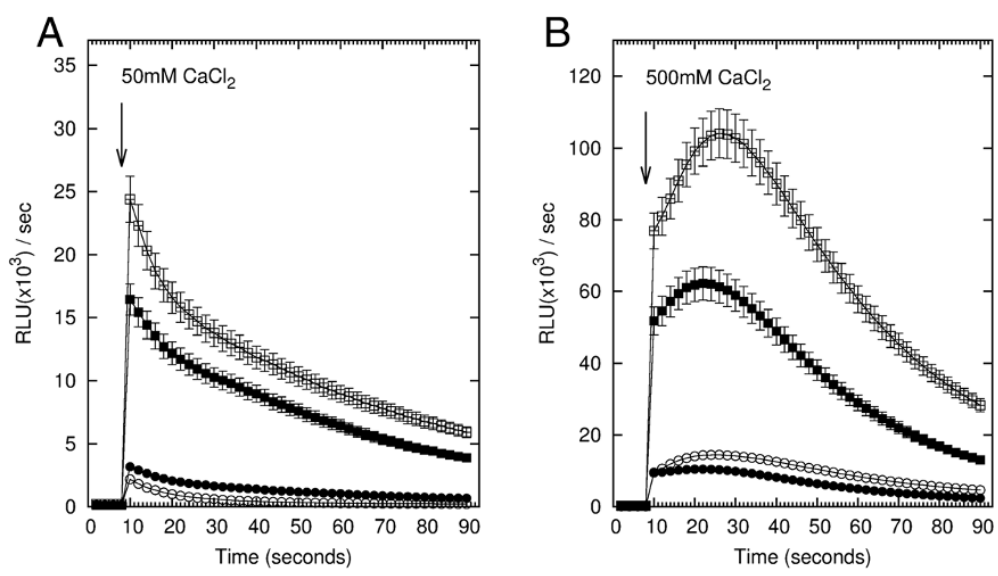

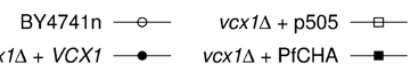

Figure 1 PfCHA rescues yeast Saccharomyces cerevisiae $\mathrm{Ca}^{2+} / \mathrm{H}^{+}$antiporter mutant. A. Apoaequorin bioluminescence of cytosolic $\mathrm{Ca}{ }^{2+}$ following exposure to extracellular $\mathrm{Ca}^{2+}$. Light emission was initially recorded for 8 seconds in low $\mathrm{Ca} 2+$ medium. $\mathrm{CaCl}_{2}$ was subsequently added to $50 \mathrm{mM}$ final concentration in $2 \mathrm{ml}$ total volume. The luminescence recorded for 90 seconds is shown. BY4741n is the haploid isogenic yeast parental strain, $v C \times 1 \Delta+$ p505 is the $v C \times 1 \Delta$ knock-out carrying the pGREG505 plasmid only, $v C \times 1 \Delta+V C X 1$ and $v C \times 1 \Delta+$ PfCHA are the same knockout strain but carrying recombinant plasmids with the homologueous VCX1 gene or the Plasmodium falciparum PfCHA gene, respectively. B. Apoaequorin luminescence measurements following a challenge with $500 \mathrm{mM}$ extracellular $\mathrm{CaCl}$. Addition of $\mathrm{CaCl} 2$ is indicated by the arrows. Data represent means and standard deviations of three experiments $(n=3)$.

Before the $\mathrm{Ca}^{2+}$ shock the luminescence of the samples were registered for 8 seconds to establish the basal line. As expected $v c x 1 \Delta$ mutant showed the highest peak of cytosolic $\mathrm{Ca}^{2+}$ level and the reference BY4741n strain presented the lowest signal with a 10 -fold difference between them. Mutant $v c x 1 \Delta$ cells expressing the homologue $V C X 1$ closely followed the $\mathrm{Ca}^{2+}$ levels of BY4741n. Significantly, $v c x 1 \Delta$ cells expressing the heterologous PfCHA also followed the extrusion of cytosolic $\mathrm{Ca}^{2+}$ after the initial peak. Although as anticipated less efficiently than the homologue $V C X 1$ gene (Figure 1A). The difference in the areas under the curve (AUC) between the cytosolic levels of $\mathrm{Ca}^{2+}$ in the mutant $v c x 1 \Delta$ carrying the plasmid control and the $v c x 1 \Delta$ carrying the recombinant plasmid with PfCHA was significant $(\mathrm{p}<0.005$, Student's two-tailed test). Replacing $\mathrm{D}$-galactose with $\mathrm{D}$-glucose, and thereby inhibiting the transcription of genes under the GAL1 promoter of the pGREG505 vector, impaired the expression of both VCX1 and PfCHA (Additional file 2). The phenotype of the $v c x 1 \Delta$ mutant and the different levels of rescue by VCX1 or PfCHA detected as cytosolic levels of $\mathrm{Ca}^{2+}$ were more apparent $(\mathrm{p}<0.0001$ and $\mathrm{p}<0.001$, respectively, Student's two-tailed test) when even higher concentrations $(500 \mathrm{mM})$ of $\mathrm{CaCl}_{2}$ were applied as external $\mathrm{Ca}^{2+}$ (Figure 1B).

$\mathrm{Ca}^{2+} / \mathrm{H}^{+}$antiporters can be inhibited by interfering with the transmembrane $\mathrm{H}^{+}$- gradient [38] and thus PfCHA was expected to be sensitive to bafilomycin $A_{1}$ a vacuolar-specific V-type ATPase inhibitor. Following a pre-incubation with bafilomycin $A_{1}(1 \mathrm{mM}$,
30 minutes) $\mathrm{Ca}^{2+}$ shock experiments were carried out as described above with $500 \mathrm{mM} \mathrm{CaCl}_{2}$. For all the strains, bafilomycin $\mathrm{A}_{1}$ treatment resulted in a reduced ability of the yeast cells to recover from the $\mathrm{Ca}^{2+}$ challenge (Figure 2). The reference strain BY4741n showed a threefold increased cytosolic $\mathrm{Ca}^{2+}$ peak (Figure 2A), while the $v c x 1 \Delta$ mutant peak response was slightly but not significantly higher in the presence of bafilomycin $\mathrm{A}_{1}$ (Figure 2A) than the DMSO control. As with the strain carrying the yeast $\mathrm{Ca}^{2+} / \mathrm{H}^{+}$exchangers $(\mathrm{p}<0.0001$, Student's two-tailed test), treatment with bafilomycin $\mathrm{A}_{1}$ also affected the ability of PfCHA-carrying yeast cells to recover from the $\mathrm{Ca}^{2+}$ challenge ( $\mathrm{p}<0.001$, Student's twotailed test) (Figure 2B). Taken together, the described phenotype rescue experiments carried out with the yeast S. cerevisiae $v c x 1 \Delta$ mutant are indicative of the functional expression of the heterologous PfCHA. Consistent with its expected mechanism of transport PfCHA is dependent on a proton membrane gradient sensitive to the vacuolarspecific inhibitor bafilomycin $A_{1}$.

\section{Further functional studies in a scalable format}

Yeast cultures of $v c x 1 \Delta$ carrying the pGREG505 vector only $(v c x 1 \Delta+\mathrm{p} 505)$ or the recombinant vectors pGREG505$V C X 1(v c x 1 \Delta+V C X 1)$ and pGREG505-PfCHA ( $v c x 1 \Delta+$ PfCHA) were processed for apoaequorin assays as described in Methods. The parental strain BY4741n was not used for assays in the multi-well plates as the mutant carrying the homologue $V C X 1$ gene behaved equivalently in the $\mathrm{Ca}^{2+}$ loading assays presented above. In 96-well 

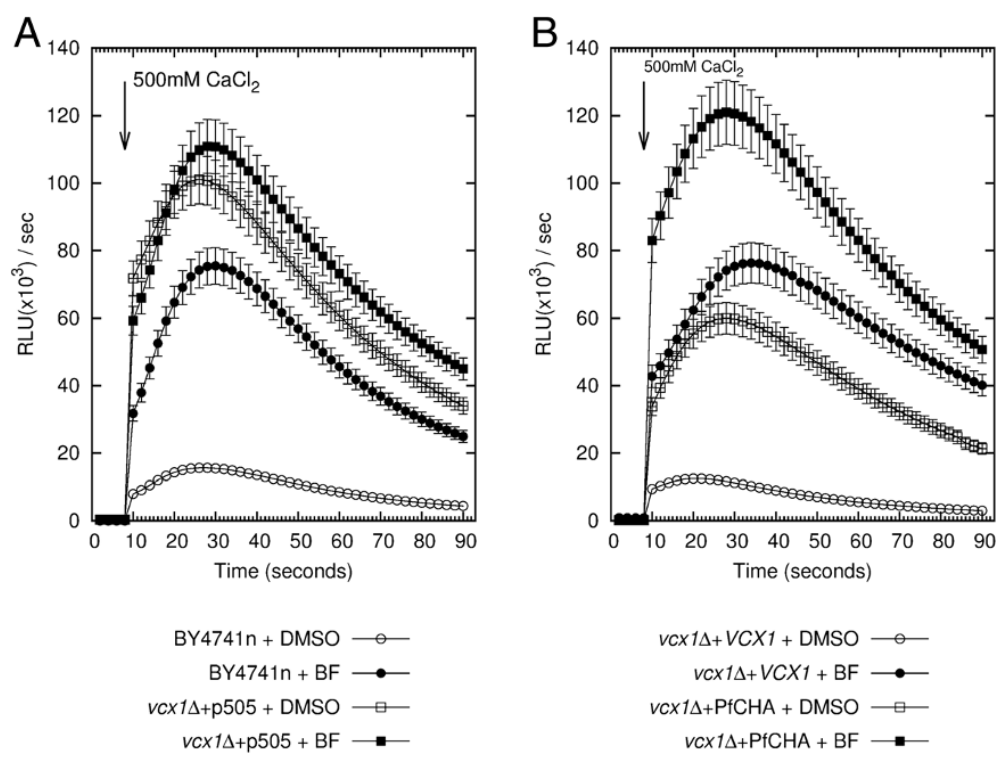

Figure 2 PfCHA Ca2+/H+ antiporter function in yeast is inhibited by bafilomycin A1. Cytoplasmic $\mathrm{Ca}^{2+}$ dependent apoaequorin luminescence was measured following pre-incubation with the V-type ATPase inhibitor bafilomycin A1 (BF). Inhibitor-free controls contained concentrations of solvent (DMSO) equivalent to the solvent present in the BF sample. A. Data from the parental BY4741n strain and the $v C \times 1 \Delta$ mutant carrying the plasmid only $(v C \times 1 \Delta+$ p505). B. $v c \times 1 \Delta$ carrying the yeast $V C X 1(v C \times 1 \Delta+V C X 1)$ or PfCHA $(v C \times 1 \Delta+$ PfCHA). Time of the addition of $\mathrm{CaCl}_{2}$ is indicated by the arrows. Data represent means of three experiments $(n=3)$.

plates yeast cells were distributed in $0.1 \mathrm{ml}$ per well containing a number of cells equivalent to 0.1 OD unit $\left(\mathrm{OD}_{600}\right)$. After establishing the base line for 5 seconds $\mathrm{Ca}^{2+}$, $\mathrm{Mg}^{2+}$ or $\mathrm{Mn}^{2+}$ were injected as $1 \mathrm{M}$ chloride salts on to the selected wells $(0.1 \mathrm{ml})$ to render $0.5 \mathrm{M}$ final concentrations. The luminescence signals were recorded for 60 seconds at intervals of 0.5 seconds. The luminescence peaks were sharper and the area under the curves was smaller than those originated by the larger cell volumes and densities used previously with equivalent final concentrations of $\mathrm{Ca}^{2+}$ (Figure 1B). The dissipation of free cytosolic $\mathrm{Ca}^{2+}$ by Vcxlp and PfCHA was significant ( $\mathrm{p}<0.001$ and $\mathrm{p}<0.01$, respectively, Student's two-tailed test) by comparison to the vector only control demonstrating the functionality of the assays in the multi-well format (Figure 3A). Furthermore, the effective movement of free $\mathrm{Mg}^{2+}$ (Figure 3B) and $\mathrm{Mn}^{2+}$ (Figure 3C) from the cytosol by PfCHA was also apparent and significant $(\mathrm{p}<0.01)$. Noteworthy, the initial functional characterization of PfCHA as a $\mathrm{Ca}^{2+}$ and $\mathrm{Mn}^{2+}$ transporter did not present direct transport activity of $\mathrm{Mg}^{2+}$ by PfCHA when expressed in X. laevis oocytes [20]. However, a lower affinity of PfCHA for $\mathrm{Mg}^{2+}$ was inferred from competition studies against ${ }^{45} \mathrm{Ca}^{2+}$ transport. Here, the yeast expression system seems to substantiate the evidence of $\mathrm{Mg}^{2+}$ being a substrate for PfCHA-mediated transport. On the other hand, the yeast Vcxlp antiporter is known to lack $\mathrm{Mn}^{2+}$ transport [39] which is in agreement with the observed lack of suppression of the $\mathrm{Mn}^{2+}$ cytosolic peak in the cells expressing the gene product of $V C X 1$ (Figure 3C).
The effective sequestration of cytosolic $\mathrm{Mg}^{2+}$ was corroborated when cells pre-loaded with $\mathrm{Mg}^{2+}(0.2 \mathrm{M}$ final concentration) had a subsequently bolus of $\mathrm{Ca}^{2+}(0.5 \mathrm{M}$ final concentration) (Figure 3D). The rationale behind this assay takes into account the fact that $\mathrm{Mg}^{2+}$ and $\mathrm{Ca}^{2+}$ share their binding sites in aequorin. Aequorin is known to bind other divalent cations besides $\mathrm{Ca}^{2+}$ via one or more of its three EF-hand $\mathrm{Ca}^{2+}$-binding sites and $\mathrm{Mg}^{2+}$ has been shown to compete for the same sites that $\mathrm{Ca}^{2+}$ occupies when bound to aequorin $[40,41]$. Thus preloading with $\mathrm{Mg}^{2+}$ will be expected to reduce any signal from a subsequent $\mathrm{Ca}^{2+}$ injection if the former has not been effectively sequestered from the cytosol. Therefore, the magnitude of the luminescence signal from $\mathrm{Ca}^{2+}$ will be in proportion to the effective sequestration of $\mathrm{Mg}^{2+}$ from cytoplasm. As observed in Figure 3D the injection of $\mathrm{Mg}^{2+}$ at 2 seconds showed the expected signal in response to the presence of this divalent cation in the cytosol. When the injection of $\mathrm{Ca}^{2+}$ followed at $5 \mathrm{sec}-$ onds, the three different cell groups presented a delayed luminescence peaks in comparison to the cells that were not pre-loaded with $\mathrm{Mg}^{2+}$ (Figure 3D). The magnitude of the luminescence peak generated by $\mathrm{Ca}^{2+}$ seems to reflect rather accurately the capacity for transport of cytoplasmic $\mathrm{Mg}^{2+}$ (Figure 3D). The $\mathrm{Ca}^{2+}$-dependent signal was respectively 12 times, 1.5 times and 3.5 times on average lower in the cells pre-loaded with $\mathrm{Mg}^{2+}$ than those that were not for $v c x 1 \Delta+\mathrm{p} 505, v c x 1 \Delta+V C X 1$ and $v c x 1 \Delta+$ PfCHA. Magnesium was then more effectively 


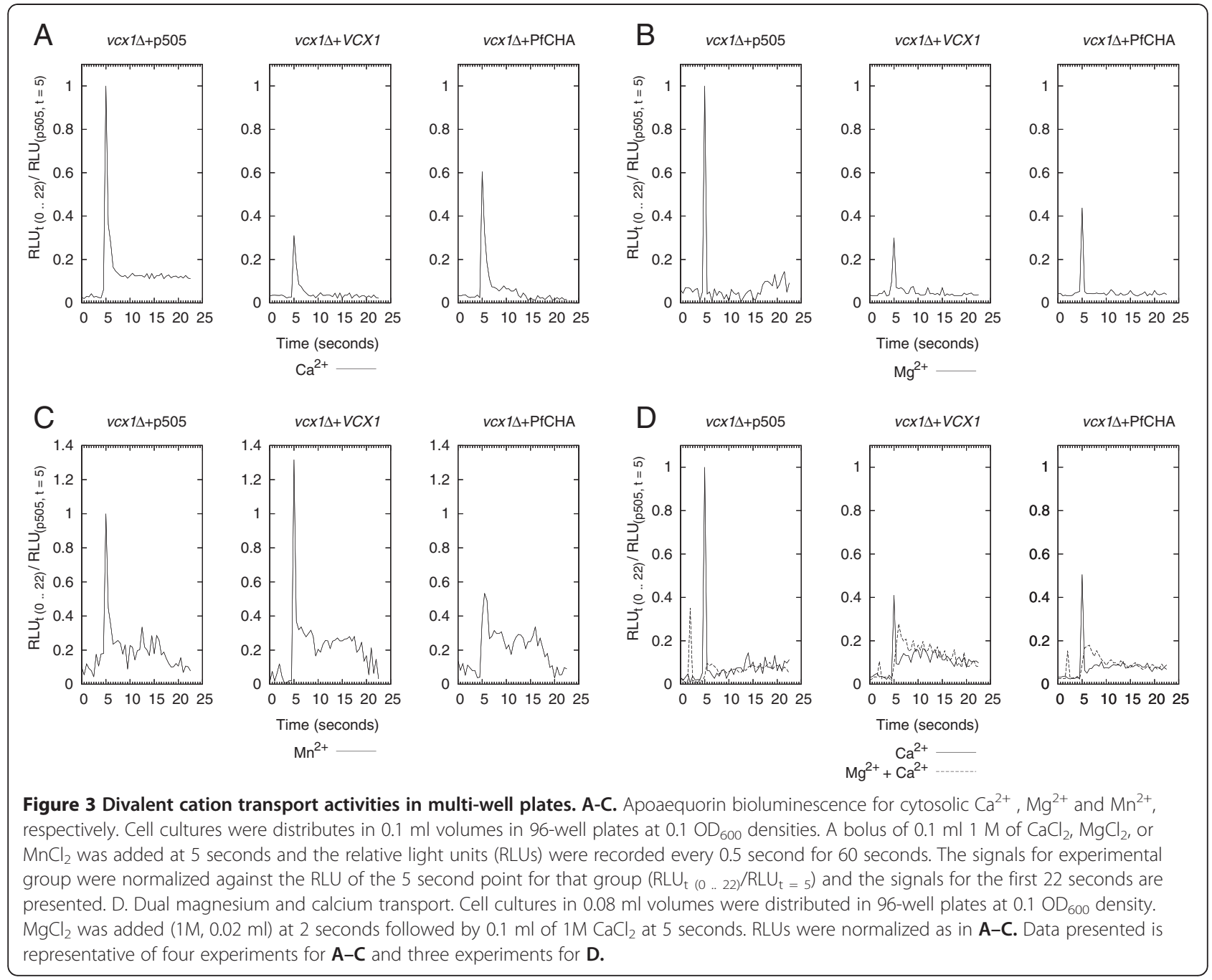

cleared in the cells carrying PfCHA followed by the yeast vcx1p antiporter and with a significantly lack of transport for $\mathrm{Mg}^{2+}$ in the knock-out stain.

PfCHA as well as Vcx1p, however, sequestered $\mathrm{Ca}^{2+}$ at slower rates when cells had been pre-loaded with $\mathrm{Mg}^{2+}$. Yeast Vcx1p dissipated the $\mathrm{Ca}^{2+}$ signal 13 times slower on average (means $0.32 \mathrm{RLUs} /$ second vs $0.025 \mathrm{RLUs} / \mathrm{sec}-$ ond) in the presence of $\mathrm{Mg}^{2+}$, with PfCHA rates of $\mathrm{Ca}^{2+}$ clearance falling to 63 times on average (means 0.44 RLUs/second $v s \quad 0.007 /$ second) significantly slower when in the presence of $\mathrm{Mg}^{2+}$. Clearance rates for $\mathrm{Ca}^{2+}$ were calculated from the highest point to the first point of the plateau for each curve $\left(\mathrm{Ca}^{2+}\right.$ only versus $\mathrm{Ca}^{2+}$ after $\mathrm{Mg}^{2+}$ load). The delayed response to cytoplasmic $\mathrm{Ca}^{2+}$ is interpreted as the time required for $\mathrm{Ca}^{2+}$ to displace $\mathrm{Mg}^{2+}$ from the aequorin EF-hand $\mathrm{Ca}^{2+}$-binding sites, and the slower clearance rates as the inhibitory effects of $\mathrm{Mg}^{2+}$ on the transport of $\mathrm{Ca}^{2+}$ by Vcx1p and PfCHA. Interestingly, by comparison PfCHA seems to be a more proficient transporter of $\mathrm{Mg}^{2+}$ given that a higher proportion was cleared from cytoplasm by $\mathrm{PfCHA}\left(\mathrm{Ca}^{2+}\right.$ peak lower in cells loaded with $\mathrm{Mg}^{2+}$ ). Also, PfCHA seems to have a higher affinity for $\mathrm{Mg}^{2+}$ than the yeast Vcxlp since the rate of $\mathrm{Ca}^{2+}$ sequestration of cytosolic $\mathrm{Ca}^{2+}$ in cells loaded with $\mathrm{Mg}^{2+}$ was most affected in the cells expression PfCHA. Pre-loading with $\mathrm{Mn}^{2+}$ was less informative due to the overlapping patterns with the signal generated by $\mathrm{Ca}^{2+}$ (data not shown). This is observed as the result of $\mathrm{Mn}^{2+}$ occupying a EF-hand $\mathrm{Ca}^{2+}$-binding site different from the two sites that $\mathrm{Ca}^{2+}$ binds in aequorin [23,24].

\section{Inhibitory assays with KB-R7943}

In the absence of specific $\mathrm{Ca}^{2+} / \mathrm{H}^{+}$antiporter inhibitors KBR7943 was used to illustrate an inhibitory assay for PfCHA using the yeast expression system. KB-R7943 is an inhibitor of $\mathrm{Na}^{+} / \mathrm{Ca}^{2+}$ antiporters [42-44] although it inhibits more avidly members of the canonical transient receptor potential channel (TRPC) family [45]. More recently KB-R7943 was used in the functional characterization of PfCHA expressed in $X$. laevis oocytes [20] where it reduced by 
approximately half the uptake of $\mathrm{Ca}^{2+}$ at $20 \mu \mathrm{M}$. Here yeast cultures were incubated for 30 minutes at room temperature in several concentrations of KB-R7943 after the cells had been treated with coelenterazine as in Methods. The effect of this inhibitor on the sequestration of cytosolic $\mathrm{Ca}^{2+}$ was apparent in all three experimental groups of the $v c x 1 \Delta$ knock-out strain carrying the empty vector pGREG505 $(v c x 1 \Delta+\mathrm{p} 505)$ or expressing $V C X 1$ $(v c x 1 \Delta+V C X 1)$ and PfCHA ( $v c x 1 \Delta+\mathrm{PfCHA})$ (Figures 4A$4 C)$. The luminescence signals increased in proportion to the concentration of KB-R7943 in all three groups: higher peak at injection time and larger areas under the curve (AUC) throughout the detection time of $60 \mathrm{sec}-$ onds. Next, the observed luminescence patterns were translated to inhibitory dose-response curves. The ratios of the AUC (between 4 and 16 seconds) of the luminescence signals from the DMSO controls over the AUC for the signals from the KB-R7943 samples were calculated and expressed as percentages for each of the three experimental groups (Figures 4D-4F). All three $v c x 1 \Delta$ yeast mutants, carrying the vector only as well as the yeast carrying Vcx1p or the Plasmodium PfCHA, had their mobilization of cytosolic $\mathrm{Ca}^{2+}$ inhibited by KB-R7943. The average concentrations $(n=4)$ at which their transport was inhibited by $50 \%$ (the AUC of the luminescence signal had double with respect to the DMSO sample) was calculated to be $7.5 \mu \mathrm{M}, 12.5 \mu \mathrm{M}$ and $17.5 \mu \mathrm{M}$ of KB-R7943 for $v c x 1 \Delta+$ pGREG505, $v c x 1 \Delta+$ $V C X 1$ and $v c x 1 \Delta+\mathrm{PfCHA}$, respectively (Figures 4D-4F). The higher sensitivity of the knock-out strain to this inhibitor in comparison to either of the $v c x 1 \Delta$ expressing the $\mathrm{Ca}^{2+} / \mathrm{H}^{+}$antiporters from yeast or Plasmodium could be explained if the $S$. cerevisiae TRPC homologue Yvc1p, a vacuolar $\mathrm{Ca}^{2+}$ - and mechanosensitive TRP cation channel, mediates the rapid initial response for sequestration of $\mathrm{Ca}^{2+}$ in $v c x 1 \Delta$ cells. TRP channels are

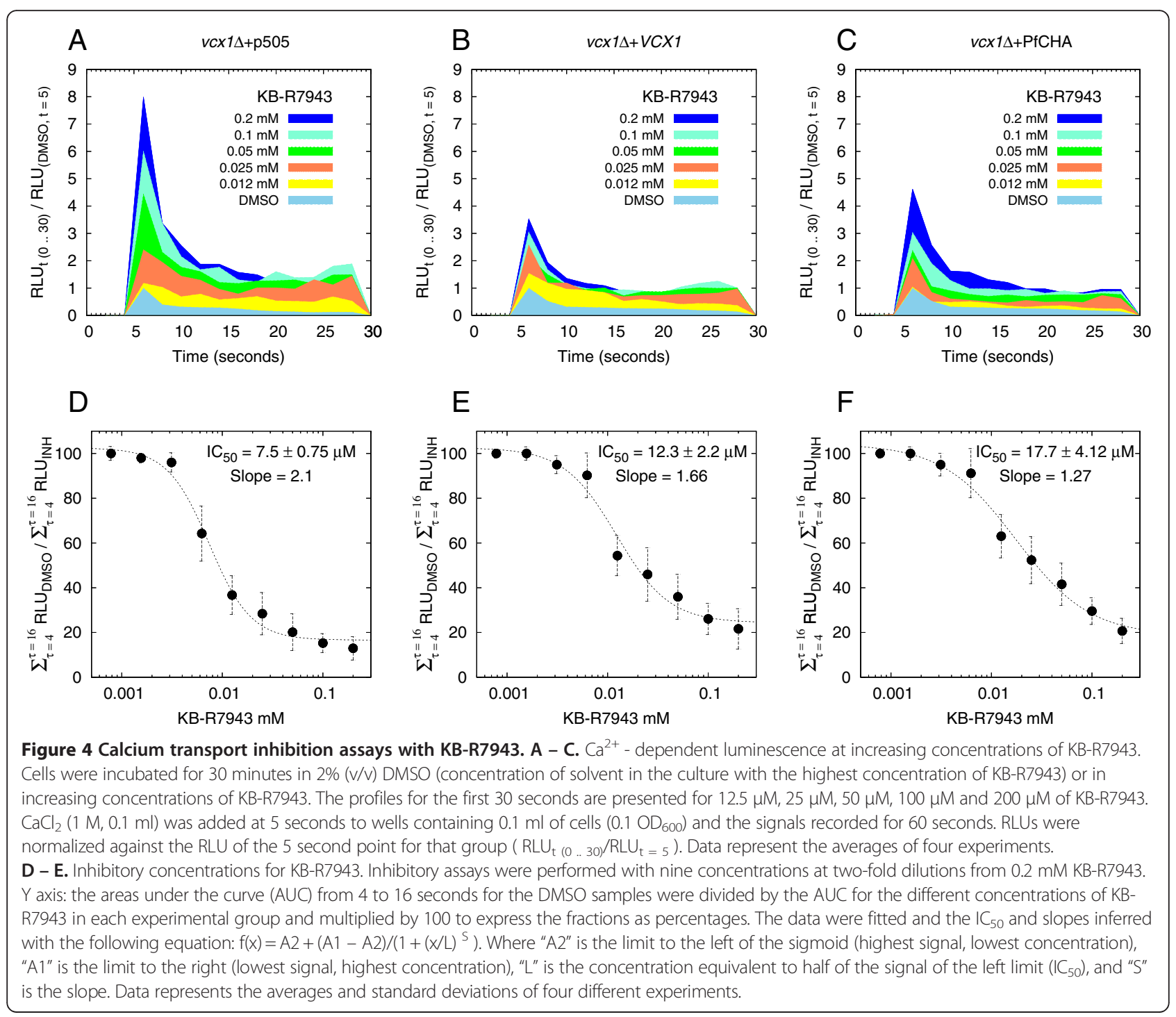


targets of KB-R7943 and have been shown to have their current blocked by $\mathrm{IC}_{50}$ in the range of $0.46-1.38 \mu \mathrm{M}$ of this inhibitor. These data therefore demonstrate the proof of concept that the yeast system using the $v c x 1 \Delta$ knock-out and apoaequorin (aequorin + coelentarazine) as a divalent cation reporter delivers a suitable screening setting for high throughput search for molecules with inhibitory activity against $P$. falciparum's $\mathrm{Ca}^{2+} / \mathrm{H}^{+}$ antiporter PfCHA.

\section{Cytolocalization of PfCHA in Saccharomyces cerevisiae}

Using a primary antibody (Anti-PfCHA) raised against a 14 aa synthetic peptide representing residues 73-86 of PfCHA, indirect immunolocalization assays were performed in the transformed yeast. Yeast $v c \times 1 \Delta$ mutants carrying pGREG505-PfCHA showed a fluorescent signal derived from the vacuole (tonoplast) (Figure 5A, bottom panels) while the control samples using the strain carrying pGREG505-VCX1 (Figure 5A, top panels) failed to generate the same fluorescent signal. The specificity of the Anti-PfCHA used here was assessed probing blots with membrane-enriched fractions of the same $v c x 1 \Delta$ mutant expressing the recombinants $V C X 1$ or PfCHA (Figure 5B). These observations in addition to the functional data presented above, indicate that in contrast to the mitochondria localization of PfCHA in P. falciparum and in the plasma membrane when expressed X. laevis [20], in S. cerevisiae the same protein is sorted to the vacuole membrane.

\section{Discussion}

A transient rise in cytosolic free $\mathrm{Ca}^{2+}$ generated when influx temporarily exceeds efflux usually functions as an intracellular signal. Calcium-proton exchangers are low- affinity cytosolic export systems that coupled to the thermodynamically downhill exchange flux of $\mathrm{H}^{+}$dissipate cytosolic increases of $\mathrm{Ca}^{2+}$ [21]. PfCHA is part of the CAXs (for CAtion eXchangers) group of integral membrane proteins that transport $\mathrm{Ca}^{2+}$ energized by the electrochemical gradient established by proton pumps such as $\mathrm{H}^{+}$-ATPases and $\mathrm{H}^{+}$-pyrophosphatases [17]. Accordingly, CAX proteins had previously been located in acidic compartments in plants [17] and yeast [21] where they sequester calcium from the cytoplasm. In P. falciparum however, the CAX homologue PfCHA seems to localize and perform $\mathrm{Ca}^{2+}$ (as well as $\mathrm{Mn}^{2+}$ ) exchange in the mitochondrion of this parasite [20]. In this organelle PfCHA is proposed to mediate the extrusion of peaks of $\mathrm{Ca}^{2+}$ from the matrix when the mitochondrion is going through transient $\mathrm{Ca}^{2+}$ overloads [20].

In order to detect functional PfCHA in S. cerevisiae, the apoaequorin luminescent response to divalent cations was used as a reporter system to follow cytosolic levels of $\mathrm{Ca}^{2+}$, $\mathrm{Mg}^{2+}$ and $\mathrm{Mn}^{2+}$ [29]. Apoaequorin bioluminescence assays in yeast have been applied in studies of cellular $\mathrm{Ca}^{2+}$ homeostasis $[34,46]$, including the functional characterization of heterologous $\mathrm{Ca}^{2+}$ transporters such as the A. thaliana $\mathrm{Ca}^{2+} / \mathrm{H}^{+}$antiporters (AtCAX) [47]. Here, PfCHA was shown to rescue the ability to mediate the dissipation of cytosolic peaks of $\mathrm{Ca}^{2+}, \mathrm{Mg}^{2+}$ and $\mathrm{Mn}^{2+}$ in the yeast $v c x 1 \Delta$ mutant and that this activity was sensitive to inhibition of the $\mathrm{H}^{+}$transmembrane gradient by a vacuolar-ATPase inhibitor as well as the $\mathrm{Na}^{+} / \mathrm{H}^{+}$antiporter and TRP channels inhibitor KB-R7943. The levels of cytosolic $\mathrm{Ca}^{2+}, \mathrm{Mg}^{2+}$ and $\mathrm{Mn}^{2+}$ reported by the apoaequorin luminescence show apparent and significant cytosolic dissipation of all three of these divalent cations by PfCHA in $v c x 1 \Delta$ cells.

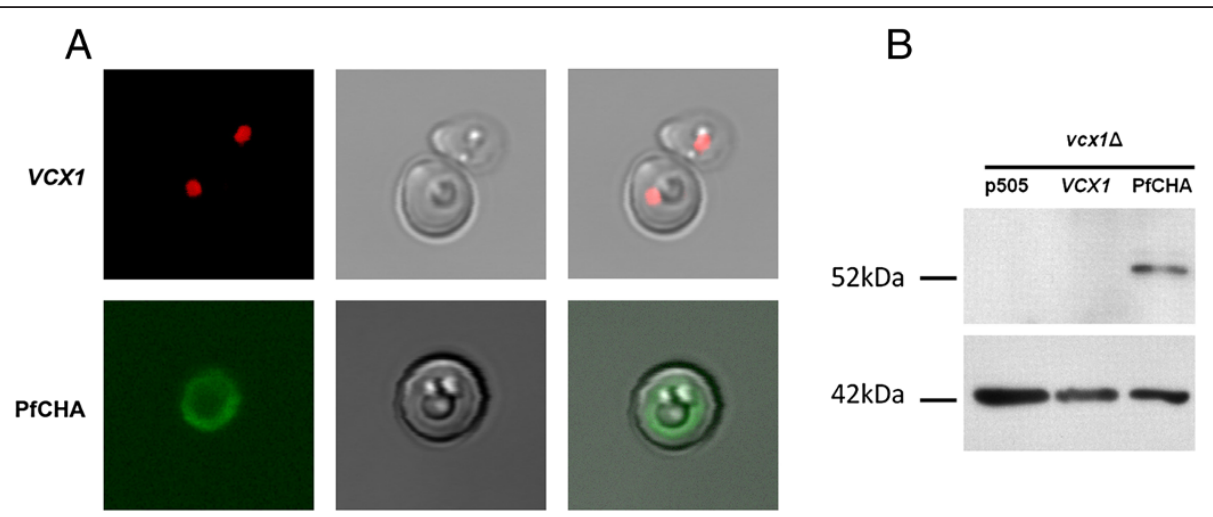

Figure 5 PfCHA protein localizes to the yeast vacuole membrane. A. Indirect immunofluorescence assay with Anti-PfCHA in yeast $v C \times 1 \triangle$ expressing the recombinants pGREG505-VCX1 and pGREG505-PfCHA. Bright field, dark field, and the merge in columns from left to right. Top panels show a sample from cells carrying pGREG505-VCX1 and stained with propidium iodide for staining of the nucleus in addition to the primary Anti-PfCHA. Bottom panels shown FITC fluorescence localizing around the yeast tonoplast of $v C X 1 \Delta$ cells carrying pGREG505-PfCHA and probed with Anti-PfCHA (1:100). B. Anti-PfCAX Western Blot. Top panel shows the signal given by Anti-PfCHA on the yeast membrane extracts. The expected molecular size for PfCHA is approximately 49kDa. Samples are labelled as the yeast vcx $1 \Delta$ mutant carrying the empty pGREG505 vector (p505), or the recombinant pGREG-VCX1 or pGREG-PfCHA vectors. Bottom panel show the control with Anti-actin antibody. Molecular mass markers as indicated. 
Taken together, the functional data and immunolocalization point at PfCHA to behave as a divalent cation $/ \mathrm{H}^{+}$exchanger that in yeast functions as a vacuolar membrane transporter. As a consequence of the role of the proton gradient in the function of this type of calcium exchanger potential inhibitors of PfCHA will have to be tested for their own capacity to inhibit proton pumps.

In yeast it is estimated that at least $90 \%$ of the total 1.5-4 mM of cellular $\mathrm{Ca}^{2+}$ is sequestered within the yeast vacuole in stable complexes (e.g. with polyphosphates) as well as free $\mathrm{Ca}^{2+}[48]$ allowing the cell basal cytosolic levels to be kept around 50-80 nM. The accumulation of vacuolar $\mathrm{Ca}^{2+}$ in yeast is maintained through the complementary action of Vcx1p $[48,49]$ and the $\mathrm{Ca}^{2+}$ ATPase Pmc1p [50]. As with other CAX proteins Vcx1p is a low affinity high capacitance facilitative $\mathrm{Ca}^{2+}$ transporter that responds to sudden increments of the cytosolic $\mathrm{Ca}^{2+}$ by rapid sequestration of this cation into the vacuole in exchange for two protons down a proton gradient (vacuolar pH 5.5-6.2 vs cytoplasmic pH 7.0) [38,51].

It is noteworthy that in S. cerevisiae, cells have to be exposed to seemingly excessive concentrations of these cations (50 mM to $500 \mathrm{mM}$ external levels of their chloride salts) in order to reach measurable cytosolic transient elevations of these ions. When exposed to 50 mM S. cerevisiae cytosolic levels of $\mathrm{Ca}^{2+}$ are measured to be in the region of $250-290 \mathrm{nM}$ (basal concentrations $50-80 \mathrm{nM}$ ) that increases further to $320-350 \mathrm{nM}$ when the external $\mathrm{Ca}^{2+}$ is raised to $400 \mathrm{mM}$ [34]. The $v c x 1 \Delta$ mutant undergoes transient elevations slightly higher with cytosolic calcium concentrations of approximately $400 \mathrm{nM}$ and $510 \mathrm{nM}$ when in the presence of $50 \mathrm{mM}$ and $400 \mathrm{mM}$ of $\mathrm{Ca}^{2+}$, respectively [34]. Coincidentally, these cytosolic concentrations of Calcium are far from the $2 \mathrm{mM}$ reported as the $\mathrm{Km}$ of PfCHA for $\mathrm{Ca}^{2+}[20]$, or the $\mathrm{Km}$ for $\mathrm{Ca}^{2+}$ reported for other CAX proteins (up to $25 \mu \mathrm{M})$ [21]. Nonetheless, the rates of divalent cations transported by PfCHA effectively dissipated $40-55 \%$ of the cytosolic transient elevations in the $v c x 1 \Delta$ background (Figures 1-Figure 3).

The localization of PfCHA to the yeast vacuole is not altogether surprising as this organelle seems to be the default localization for foreign proteins in S. cerevisiae. In $S$. cerevisiae proteins are sorted to the vacuole by at least four different pathways [52]: (i) sorting of vacuolar proteins $v s$ cell surface proteins in the early stages of the secretory pathway, (ii) endocytic engulfing of material from the plasma membrane, (iii) cytoplasm-to-vacuole targeting pathways that do not transit the early stages of the secretory pathway, and (iv) the de facto inheritance of vacuolar material by daughter cells during cell division. However, in S. cerevisiae membrane proteins lacking motifs or otherwise protein structure information for cellular localization are predominantly delivered to the vacuole membrane [53,54]. Moreover, membrane proteins have been shown to be delivered by default to the yeast vacuole when high levels of protein expression overexpression - are achieved. The localization of membrane proteins depends also on the length of their transmembrane domains [53], it is not possible to know a priori the destination of a membrane transporter in a heterologous expression system. In the yeast expression system as reported here it is speculated that PfCHA is sorted by a default mechanism to the yeast vacuole [55].

In eukaryotic cell hosts, the yeast $S$. cerevisiae is by far the most advantageous gene expression system since it is relatively inexpensive to culture and it is the most genetically tractable eukaryotic system with excellent recombinant DNA tools. Additionally, recent advances seeking to overcome the difficulties intrinsic to the expression of foreign proteins in yeast, particularly membrane proteins, have rendered transgenic strains with altered ribosomal content that seems to tolerate and much improve heterologous gene overexpression [56,57]. The successful expression of PfCHA in S. cerevisiae and its localization to the yeast vacuole permits a very tractable system for further functional and pharmacological studies as exemplified here in multi-well whole-cell cation transport and inhibitory assays.

\section{Conclusions}

Yeast offers a cost-effective and user-friendly gene expression system for further functional studies and pharmacological screens of proteins from $P$. falciparum. Particularly membrane transporters such as PfCHA that are still very seldom successfully expressed in heterologous hosts. Moreover, the bioluminescence assay for the detection of cytoplasmic $\mathrm{Ca}^{2+}$ as well as $\mathrm{Mg}^{2+}$ and $\mathrm{Mn}^{2+}$ lends itself to high-throughput and quantitative settings.

\section{Additional files}

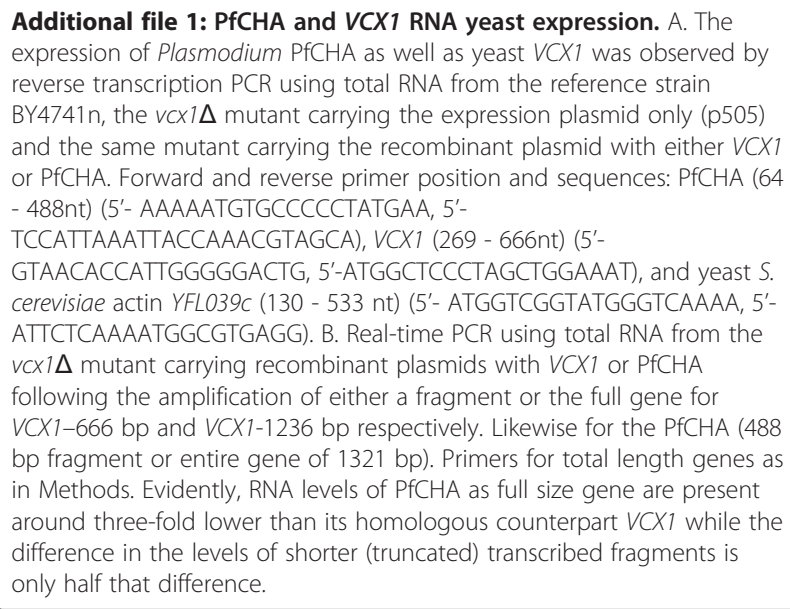


Additional file 2: Phenotypic rescue of yeast Saccharomyces cerevisiae vcx $1 \Delta$ inhibited in presence of glucose. Conditions and strains as in Figure $1 \mathrm{~A}$ except that the culture medium contained Dglucose instead of D-galactose which suppresses the activity of the GAL1 promoter present in pGREG505.

\section{Abbreviations}

PfCHA: Plasmodium falciparum $\mathrm{Ca}^{2+} / \mathrm{H}^{+}$antiporter; VCX1: Saccharomyces cerevisiae; $\mathrm{Ca}^{2+} / \mathrm{H}^{+}$antiporter; RLU: Relative Light Units.

\section{Competing interests}

The authors declare that they have no competing interests.

\section{Authors' contributions}

JES-S designed the study and performed experiments. JES-S and GAB wrote the initial draft of the manuscript. SAW and GAB edited and revised the manuscript, and provided materials and equipment. All authors read and approved the final manuscript.

\section{Acknowledgement}

This work was supported by the MRC grant G0400173.

Received: 19 May 2012 Accepted: 23 July 2012

Published: 1 August 2012

\section{References}

1. Raventos Suarez C, Bookchin RM, Lew D, Nagel R, Lew VL: Ca2+ is required forreinfection of red cells by Plasmodium falciparum. Fed Proc 1982, 41:1121.

2. Singh S, Alam MM, Pal-Bhowmick I, Brzostowski JA, Chitnis CE: Distinct external signals trigger sequential release of apical organelles during erythrocyte invasion by malaria parasites. PLOS Pathog 2010, 6:e1000746.

3. Wasserman $M$, Chaparro J: Intraerythrocytic calcium chelators inhibit the invasion of Plasmodium falciparum. Parasitol Res 1996, 82:102-107.

4. Hotta CT, Gazarini ML, Beraldo FH, Varotti FP, Lopes C, Markus RP, Pozzan T, Garcia CR: Calcium-dependent modulation by melatonin of the circadian rhythm in malarial parasites. Nat Cell Biol 2000, 2:466-468.

5. Billker O, Dechamps S, Tewari R, Wenig G, Franke-Fayard B, Brinkmann V: Calcium and a calcium-dependent protein kinase regulate gamete formation and mosquito transmission in a malaria parasite. Cell 2004, 117:503-514.

6. Ishino T, Orito Y, Chinzei Y, Yuda M: A calcium-dependent protein kinase regulates Plasmodium ookinete access to the midgut epithelial cell. Mol Microbiol 2006, 59:1175-1184.

7. Ono T, Cabrita-Santos L, Leitao R, Bettiol E, Purcell LA, Diaz-Pulido O, Andrews LB, Tadakuma T, Bhanot P, Mota MM, Rodriguez A: Adenylyl cyclase alpha and CAMP signaling mediate Plasmodium sporozoite apical regulated exocytosis and hepatocyte infection. PLoS Pathog 2008, 4: e1000008.

8. Alleva L, Kirk K: Calcium regulation in the intraerythrocytic malaria parasite Plasmodium falciparum. Mol Biochem Parasitol 2001, 117:121-128.

9. Biagini $G$, Bray P, Spiller D, White M, Ward S: The digestive food vacuole of the malaria parasite is a dynamic intracellular $\mathrm{Ca} 2+$ store. J Biol Chem 2003, 278:27910-27915.

10. Krishna S, Woodrow C, Webb R, Penny J, Takeyasu K, Kimura M, East JM: Expression and functional characterization of a Plasmodium falciparum Ca2 +- ATPase (PfATP4) belonging to a subclass unique to apicomplexan organisms. J Biol Chem 2001, 276:10782-10787.

11. Eckstein-Ludwig U, Webb RJ, Van Goethem ID, East JM, Lee AG, Kimura M, O'Neill PM, Bray PG, Ward SA, Krishna S: Artemisinins target the SERCA of Plasmodium falciparum. Nature 2003, 424:957-961.

12. Kimura M, Yamaguchi Y, Takada S, Tanabe K: Cloning of a Ca(2+)-ATPase gene of Plasmodium falciparum and comparison with vertebrate $\mathrm{Ca}$ (2+)-ATPases. J Cell Sci 1993, 104:1129-1136

13. Marchesini N, Luo S, Rodrigues CO, Moreno SN, Docampo R: Acidocalcisomes and a vacuolar $\mathrm{H}+$-pyrophosphatase in malaria parasites. Biochem J 2000, 347(Pt 1):243-253.

14. Ruiz FA, Luo S, Moreno SNJ, Docampo R: Polyphosphate Content and Fine Structure of Acidocalcisomes of Plasmodium falciparum. Microsc Microanal 2004, 10:563-567.
15. Gazarini ML, Garcia CR: The malaria parasite mitochondrion senses cytosolic Ca2+ fluctuations. Biochem Biophys Res Commun 2004, 321:138-144.

16. Rohrbach P. Friedrich O, Hentschel J, Plattner H, Fink RHA, Lanzer M: Quantitative calcium measurements in subcellular compartments of Plasmodium falciparum-infected erythrocytes. J Biol Chem 2005, 280:27960-27969.

17. Shigaki T, Hirschi KD: Diverse functions and molecular properties emerging for cax cation/ $\mathrm{h}$ + exchangers in plants. Plant Biol 2006, 8:419-429.

18. Shigaki T, Rees I, LN, Hirschi KD: Identification of three distinct phylogeneticgroups of CAX cation/proton antiporters. J Mol Evol 2006, 63:815-825

19. Saier MHJ: A functional-phylogenetic classification system for transmembrane solute transporters. Microbiol Mol Biol Rev 2000, 64:354-411.

20. Rotmann A, Sanchez C, Guiguemde A, Rohrbach P, Dave A, Bakouh N, Planelles G, Lanzer M: PfCHA is a mitochondrial divalent cation/ $\mathrm{H}+$ antiporter in Plasmodium falciparum. Mol Microbiol 2010 76:1591-1606

21. Pittman JK: Vacuolar $\mathrm{Ca}^{2+}$ uptake. Cell Calcium 2011, 50:139-146.

22. Ton $V$, Rao R: Functional expression of heterologous proteins in yeast: insights into $\mathrm{Ca} 2+$ signaling and $\mathrm{Ca} 2$ +-transporting ATPases. Am J Physiol Cell Physiol 2004, 287:C580-C589.

23. Izutsu K, Felton S, Siegel I, Yoda W, Chen A: Aequorin: Its ionic specificity. Biochem Biophys Res Commun 1972, 49:1034-1039.

24. Kemple MD, Lovejoy ML, Ray BD, Prendergast FG, Nageswara Rao BD: Mn (II)-EPR measurements of cation binding by aequorin. Eur J Biochem 1990, 187:131-135.

25. Trager W, Jensen JB: Human malaria parasites in continuous culture. Science 1976, 193:673-675

26. Aurrecoechea C, Brestelli J, Brunk BP, Dommer J, Fischer S, Gajria B, Gao X, Gingle A, Grant G, Harb OS, Heiges M, Innamorato F, lodice J, Kissinger JC, Kraemer E, Li W, Miller JA, Nayak V, Pennington C, Pinney DF, Roos DS, Ross C, Stoeckert, Christian J Jr, Treatman C, Wang H: PlasmoDB: a functional genomicdatabase for malaria parasites. Nucleic Acids Res 2009, 37: D539-D543.

27. Benson DA, Karsch-Mizrachi I, Lipman DJ, Ostell J, Wheeler DL: GenBank. Nucleic Acids Res 2008, 36:D25-D30.

28. Jansen G, Wu C, Schade B, Thomas DY, Whiteway M: Drag\&Drop cloning in yeast. Gene 2005, 344:43-51.

29. Nakajima-Shimada J, lida H, Tsuji F, Anraku Y: Monitoring of intracellular calcium in Saccharomyces cerevisiae with an apoaequorin CDNA expression system. Proc Natl Acad Sci U S A 1991, 88:6878-6882.

30. European Saccharomyces cerevisiae archive for functional analysis. web.unifrankfurt.de/fb15/mikro/euroscarf/.

31. Saccharomyces Genome Database. www.yeastgenome.org/

32. Hill J, Donald KG, Griffiths DE: DMSO-enhanced whole cell yeast transformation. Nucleic Acids Res 1991, 19:5791.

33. Ausubel F, Brent R, Kingston R, Moore D, Seidman J, Smith J, Struhl K: Shortprotocols in molecular biology. Wiley 2002

34. Miseta A, Kellermayer R, Aiello DP, Fu LW, Bedwell DM: The vacuolar Ca2 $+/ \mathrm{H}+$ exchanger Vcx1p/Hum1p tightly controls cytosolic Ca2+ levels in $S$. cerevisiae. FEBS Lett 1999, 451:132-136.

35. Fisher N, Warman AJ, Ward SA, Biagini GA: Type II NADH: Quinone oxidoreductases of Plasmodium falciparum and Mycobacterium tuberculosis: kinetic and high-throughput assays. Methods Enzymol 2009, 456:303-320.

36. Stearman R, Yuan DS, Yamaguchi-Iwai Y, Klausner RD, Dancis A: A Permease- oxidase complex involved in high-affinity iron uptake in yeast. Science 1996, 271:1552-1557.

37. Salcedo E, Cortese JF, Plowe CV, Sims PFG, Hyde JE: A bifunctional dihydrofolate synthetase-folylpolyglutamate synthetase in Plasmodium falciparum identified by functional complementation in yeast and bacteria. Mol Biochem Parasitol 2001, 112:239-252.

38. Preston R, Murphy R, Jones E: Assay of vacuolar $\mathrm{pH}$ in yeast and identification of acidification-defective mutants. Proc Natl Acad Sci U S A 1989, 86:7027-7031.

39. Pittman JK, Cheng NH, Shigaki T, Kunta M, Hirschi KD: Functional dependence on calcineurin by variants of the Saccharomyces cerevisiae vacuolar Ca2+/H+ exchanger Vcx1p. Mol Microbiol 2004, 54:1 104-1116. 
40. Jones K, Hibbert F, Keenan M: Glowing jellyfish, luminescence and a molecule called coelenterazine. Trends Biotechnol 1999, 17:477-481.

41. Kendall JM, Badminton MN: Aequorea victoria bioluminescence moves into an exciting new era. Trends Biotechnol 1998, 16:216-224.

42. Elias CL, Lukas A, Shurraw S, Scott J, Omelchenko A, Gross GJ, Hnatowich M, Hryshko LV: Inhibition of Na+/Ca2+ exchange by KB-R7943: transport mode selectivity and antiarrhythmic consequences. Am J Physiol Heart Circ Physiol 2001, 281:H1334-H1345.

43. Iwamoto T, Watano T, Shigekawa M: A novel isothiourea derivative selectively inhibits the reverse mode of $\mathrm{Na}+/ \mathrm{Ca} 2+$ Exchange in Cells Expressing NCX1. J Biol Chem 1996, 271:22391-22397.

44. Watano T, Kimura J, Nakanishi H: A novel antagonist, No. 7943, of the Na $+/ \mathrm{Ca} 2+$ exchange current in guinea-pig cardiac ventricular cells. $\mathrm{Br} \mathrm{J}$ Pharmacol 1996, 119:555-563.

45. Kraft $\mathrm{R}$ : The $\mathrm{Na}+/ \mathrm{Ca} 2+$ exchange inhibitor KB-R7943 potently blocks TRPC channels. Biochem Biophys Res Commun 2007, 361:230-236.

46. Batiza A, Schulz T, Masson P: Yeast respond to hypotonic shock with a Calcium pulse. J Biol Chem 1996, 271:23357-23362.

47. Hirschi KD, Zhen RG, Cunningham KW, Rea PA, Fink GR: CAX1, an H+/Ca2+ antiporter from Arabidopsis. Proc Natl Acad Sci U S A 1996, 93:8782-8786.

48. Cunningham KW, Fink GR: Calcineurin inhibits VCX1-dependent $\mathrm{H}+/ \mathrm{Ca} 2+$ exchange and induces Ca2+ ATPases in Saccharomyces cerevisiae. Mol Cell Biol 1996, 16:2226-2237.

49. Pozos TC, Sekler I, Cyert MS: The product of HUM1, a novel yeast gene, is required for vacuolar $\mathrm{Ca} 2+/ \mathrm{H}+$ exchange and is related to mammalian $\mathrm{Na}+/ \mathrm{Ca} 2+$ exchangers. Mol Cell Biol 1996, 16:3730-3741.

50. Cunningham KW, Fink GR: Calcineurin-dependent growth control in Saccharomyces cerevisiae mutants lacking PMC1, a homolog of plasma membrane Ca2+ ATPases. J Cell Biol 1994, 124:351-363.

51. Carmelo V, Santos H, Sa-Correia I: Effect of extracellular acidification on the activity of plasma membrane ATPase and on the cytosolic and vacuolar pH of Saccharomyces cerevisiae. Biochim Biophys Acta Biomembranes 1997, 1325:63-70.

52. Bryant NJ, Stevens TH: Vacuole biogenesis in Saccharomyces cerevisiae: protein transport pathways to the yeast vacuole. Microbiol Mol Biol Rev 1998, 62:230-247.

53. Rayner JC, Pelham HRB: Transmembrane domain-dependent sorting of proteins to the ER and plasma membrane in yeast. EMBO J 1997, 16:1832-1841.

54. Wilcox CA, Redding K, Wright R, Fuller RS: Mutation of a tyrosine localization signal in the cytosolic tail of yeast Kex2 protease disrupts Golgi retention and results in default transport to the vacuole. Mol Biol Cell 1992, 3:1353-1371.

55. Roberts CJ, Nothwehr SF, Stevens TH: Membrane protein sorting in the yeast secretory pathway: evidence that the vacuole may be the default compartment. J Cell Biol 1992, 119:69-83.

56. Ashe MP, Bill RM: Mapping the yeast host cell response to recombinant membrane protein production: Relieving the biological bottlenecks. Biotechnol J 2011, 6:707-714.

57. Bawa Z, Bland CE, Bonander N, Bora N, Cartwright SP, Clare M, Conner MT, Darby RA, Dilworth MV, Holmes WJ, Jamshad M, Routledge SJ, Gross SR, Bill $\mathrm{RM}$ : Understanding the yeast host cell response to recombinant membrane protein production. Biochem Soc Trans 2011, 39:719-723.

\section{Submit your next manuscript to BioMed Central and take full advantage of:}

- Convenient online submission

- Thorough peer review

- No space constraints or color figure charges

- Immediate publication on acceptance

- Inclusion in PubMed, CAS, Scopus and Google Scholar

- Research which is freely available for redistribution

Submit your manuscript at www.biomedcentral.com/submit
C) Biomed Central 